\title{
APLICAÇÃO DO MÉTODO ELETROMAGNÉTICO INDUTIVO NA INVESTIGAÇÃO DA PLUMA DE CONTAMINAÇÃO DA ÁGUA SUBTERRÂNEA POR RESÍDUOS DE CROMO DE CURTUME
}

\author{
Luiz Fernando Jorge da Cunha ${ }^{1}$ e Shozo Shiraiwa² \\ Recebido em 16 novembro, 2009 / Aceito em 31 março, 2010 \\ Received on November 16, 2009 / Accepted on March 31, 2010
}

\begin{abstract}
This paper presents the results obtained with the inductive electromagnetic method EM-34, used to describe the contamination plume in aquifer due to wastes of tanning residues in Várzea Grande, district, Mato Grosso State. This area was used for more than ten years as a place of disposal of sludge from tanning in ditches previously excavated in the soil. This area is currently seal off by the environmental govern. The results obtained with the application of electromagnetic inductive method showed that the level of $7.5 \mathrm{~m}$ and $15.0 \mathrm{~m}$ below the surface the soil conductivity on the ditch was approximately 2 to 3 times higher than the values measured on the road circulating the area of deposition. The highest values of apparent conductivity could also be related to higher concentrations of chromium in groundwater according to data obtained from chemical analysis conducted on water collected in wells tracking (SEMA). The tests in the area show the need to maintain a constant monitoring of the region due to the possibility of slow migration of contaminants to areas adjacent to the deposit.
\end{abstract}

Keywords: groundwater, contamination, inductive electromagnetic, tanning.

RESUMO. Este trabalho apresenta os resultados obtidos com a aplicação do método eletromagnético indutivo, para descrever a estrutura aquífera e eventual contaminação relacionada a resíduos de couro no distrito de Capão Grande, em Várzea Grande, Estado de Mato Grosso. Esta área fora utilizada por mais de 10 anos como local de descarte de lodo de curtume em valas previamente escavadas no solo, estando atualmente interditada pela SEMA-MT - Secretaria de Estado do Meio Ambiente de Mato Grosso. Os resultados obtidos com a aplicação do método eletromagnético indutivo mostraram que tanto no nível de 7,5 m como de $15,0 \mathrm{~m}$ da superfície do solo, a condutividade do solo sobre a vala foi aproximadamente 2 a 3 vezes superior a obtida na linha sobre a estrada, margeando a área de deposição. Os maiores valores de condutividade aparente puderam também ser relacionados às maiores concentrações de cromo na água subterrânea através de dados obtidos do trabalho de investigação direta (análise química da água coletada em quatro poços de monitoramento realizados pela SEMA). Os ensaios realizados na área comprovam a necessidade de se manter um monitoramento constante da região pela possibilidade de migração lenta dos resíduos para outras áreas adjacentes àquela do depósito interditado em regiões com densidade populacional maior e sem conhecimento dos perigos da utilização da água do lençol freático.

Palavras-chave: água subterrânea, contaminação, eletromagnético indutivo, curtume.

\footnotetext{
${ }^{1}$ FACIEX-UNEMAT-Brasil, Departamento de Matemática, Universidade do Estado de Mato Grosso, Av. São João s/n, Bairro Cavalhada, 78200-000 Cáceres, MT, Brasil. Tel.: (65) 3221-0510 - E-mail: engeda@terra.com.br

2 IF-UFMT-Brasil, Departamento de Física, Universidade Federal de Mato Grosso, Av. Fernando Correia da Costa s/n, Bloco F/Sala 224, ICET, 78060-900 Cuiabá, MT, Brasil. Tel.: (65) 3615-8745/8751; Fax: (65) 3615-8764 - E-mail: shozo@cpd.ufmt.br
} 


\section{INTRODUÇÃo}

0 Brasil é um dos cinco maiores produtores de peles bovinas do mundo, ocupando a posição de liderança entre os países da América Latina, com 4,5\% da produção mundial. Contudo, não apresenta a mesma performance quando diz respeito à produção de couros acabados. Mais de dois terços da produção de couros no país é feita no estágio Wet-Blue, de baixo valor agregado, ficando com mais de $80 \%$ da poluição gerada na industrialização do couro.

Com o maior rebanho bovino do Brasil, estimado em mais de 20 milhões de cabeças, Mato Grosso vem aumentando gradativamente a sua participação na atividade industrial do processo de curtimento de peles. Apesar desse aumento receber incentivo do governo estadual, com o estabelecimento de uma cadeia produtiva do couro, a disposição dos resíduos no solo proveniente desta atividade, vem sendo realizada sem atender alguns parâmetros de controle e sem considerar as especificidades locais. As novas e modernas indústrias de processamento têm seguido normas gerais, contudo pouco se avançou na adequação local.

Segundo Elis (2003), a contaminação das águas subterrâneas está relacionada com a forma de disposição dos resíduos e efluentes e com a falta de um planejamento sobre a seleção de área adequada, levando-se em consideração essencialmente três constituintes geológicos: propriedades dos solos que os qualifiquem para material de cobertura das células de resíduos; condições de drenagem superficial dos terrenos e condições de drenabilidade de solos e rochas.

Os parâmetros de poluição da indústria de couros acabados tipo vaqueta, por tonelada de peles processadas são: 75 a $90 \mathrm{~kg}$ de demanda bioquímica de oxigênio (DB0); 200 a 260 kg de demanda química de oxigênio (DQ0); 140 kg de sólidos em suspensão; $12,6 \mathrm{~kg}$ de nitrogênio total; 9,0 kg de sulfetos; $5,0 \mathrm{~kg}$ de cromo total e $55 \mathrm{~m}^{3}$ de águas residuárias (Koetz et al., 1995).

Os resíduos de curtume não convenientemente tratados podem atingir o lençol freático, reservatórios e rios com alto poder de contaminação. Nestes resíduos o cromo apresenta-se na forma trivalente $\mathrm{Cr}^{3+}$, mais estável e considerado menos tóxico, de baixa solubilidade e mobilidade, em razão de sua precipitação como óxidos e hidróxidos em pH superior a 5. Porém, o seu acúmulo associado a determinadas condições do solo, aliado a baixos teores de carbono orgânico e boa aeração, promovem a sua oxidação formando 0 cromo hexavalente $\mathrm{Cr}^{+6}$, tóxico, mutagênico, e solúvel em uma ampla faixa de pH, com muita mobi- lidade no sistema solo/água (Ray et al., 1989). É esta solução eletrolítica que aumenta consideravelmente a condutividade da água subterrânea facilitando medidas de condutividade da subsuperfície através do emprego do método eletromagnético indutivo.

Neste trabalho investigou-se a área atingida pela infiltração dos resíduos descartados no terreno, procurando monitorar a sua mobilidade e possibilidade de poluição do aquífero freático.

\section{LOCALIZAÇÃO DA ÁREA}

A área em que se encontra o depósito de resíduos, alvo de investigação deste trabalho, está localizada no município de Várzea Grande em Mato Grosso (Fig. 1).

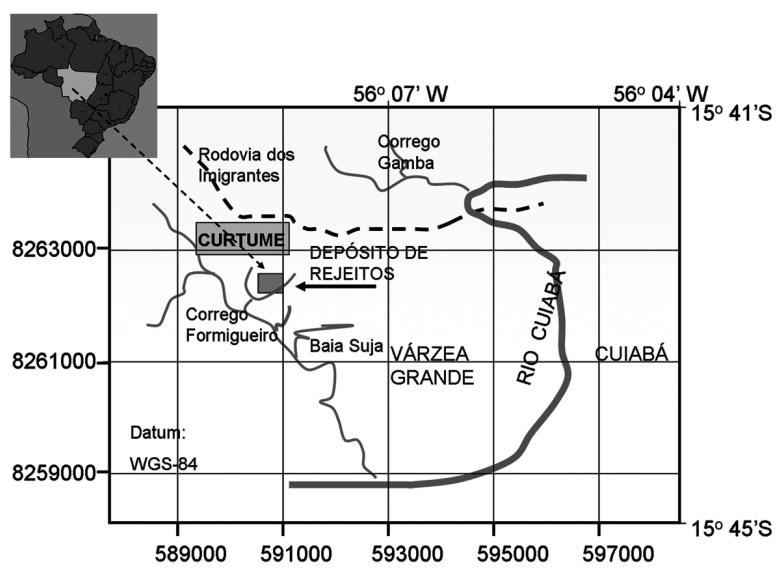

Figura 1 - Mapa de localização da área de estudo.

Distando aproximadamente $4 \mathrm{~km}$ da indústria, esta área fora utilizada por um período aproximado de 10 anos como depósito de resíduos proveniente do processo de industrialização do couro. Este resíduo era disposto em valas de aproximadamente 2,5 $\mathrm{m}$ de largura por 2,5 $\mathrm{m}$ de profundidade e comprimento indeterminado, onde era usada uma lona de $0,3 \mathrm{~mm}$ que se mostrou inadequada para assegurar a impermeabilização.

Análises químicas da água subterrânea, em amostras coletadas em 4 poços de monitoramento localizados na área, indicaram a presença de cromo na água em concentrações muito mais elevadas que os permitidos pela legislação $(0,05 \mathrm{mg} / \mathrm{L})$ (Ministério da Saúde, 2004; Lannes, 2002). Assim a área foi interditada pela SEMA-MT (Secretaria de Estado do Meio Ambiente de Mato Grosso).

A área estudada se insere regionalmente na denominada Depressão Cuiabana e compreende uma extensa área rebaixada (relevo de planície), com altitudes entre 150 a $200 \mathrm{~m}$, entre 0 Planalto dos Guimarães e a Província Serrana. Limita-se ao sul com o Pantanal Mato-grossense, a oeste, noroeste e norte com a 
Província Serrana. 0 Planalto dos Guimarães constitui seu limite leste. Esta área está inserida na formação Rio Coxipó, tendo duas associações litológicas principais: a dos metadiamictitos com matrizes argilosas, maciços, com raras intercalações de areias fina a média e a dos metadiamictitos, com matrizes arenosas, intercalados a arenitos quartzosos grossos e médios (Migliorini, 1999). Na Figura 2 estão apresentadas as curvas de nível do terreno estudado.

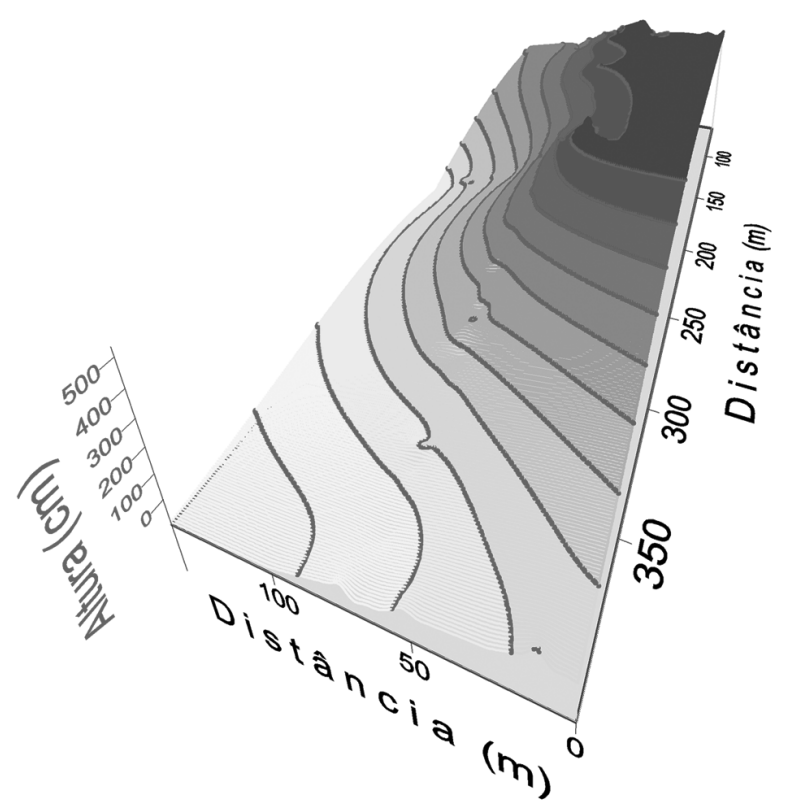

Figura 2 - Curvas de nível do terreno.

\section{METODOLOGIA}

0 método utilizado nesta pesquisa foi 0 eletromagnético indutivo. Como existia a possibilidade da pluma contaminante estar disseminada pelo subsolo na área procurou-se fazer um mapeamento da condutividade aparente em diversos níveis. 0 princípio do método consiste na passagem de corrente elétrica alternada em uma bobina transmissora, gerando um campo eletromagnético primário. Correntes secundárias são induzidas em um meio condutor no subsolo, que por sua vez geram um campo eletromagnético secundário. A presença de meios condutores pode ser verificada pela bobina receptora monitorando as diferenças de intensidade e fase geradas pelos campos primário e secundário.

Para fazer um mapeamento da condutividade em diversos níveis foram utilizadas as configurações de bobinas coplanares na horizontal (dipolo magnético vertical) e bobinas coplanares na vertical (dipolo magnético horizontal). 0 trabalho foi realizado com 0 equipamento EM-34-3 da Geonics Ltd. Este modelo de equipamento fornece a leitura direta da condutividade aparente que é realizada através da conversão da componente em quadratura do campo magnético em milisiemens por metro $(\mathrm{mS} / \mathrm{m})$ (McNeill, 1980). A expressão que traduz a condutividade aparente é fornecida por

$$
\sigma_{a}=\frac{4}{\mu \omega r^{2}}\left(\frac{H_{s}}{H_{p}}\right),
$$

onde $\mu$ é a permeabilidade magnética; $\omega$ é frequência angular; $r$ é a distância entre as bobinas; $H_{S}$ campo magnético secundário e $H_{p} 0$ campo magnético primário.

A distância entre as bobinas transmissora e receptora utilizadas foram de 10, 20 e 40 metros com as frequências de 6,4; 1,6 e $0,4 \mathrm{kHz}$ respectivamente. As medidas foram efetuadas nos dipolos magnéticos horizontal e vertical, permitindo um alcance de profundidade teórica estimada de 7,5; 15; 30 e 60 m (Tab. 1). Para 0 desenho das curvas de isovalores de condutividade elétrica nos mapas ou perfis, o método de interpolação utilizado foi a krigagem ordinária (Landim, 2003) feita com a utilização do software SURFER, versão 8, Golden Software (Golden, 1995).

Tabela 1 - Profundidades de investigação obtidas através da combinação do espaçamento das bobinas, da orientação dos dipolos e da frequência do sinal.

\begin{tabular}{|c|c|c|c|}
\hline \multirow{2}{*}{$\begin{array}{c}\text { Distância entre } \\
\text { as bobinas } \\
(\mathrm{m})\end{array}$} & $\begin{array}{c}\text { Frequência } \\
(\mathrm{Hz})\end{array}$ & \multicolumn{2}{|c|}{$\begin{array}{c}\text { Profundidade teórica de investigação } \\
(\mathrm{m})\end{array}$} \\
\cline { 3 - 4 } & & $\begin{array}{c}\text { Dipolo horizontal } \\
(\mathrm{m})\end{array}$ & $\begin{array}{c}\text { Dipolo vertical } \\
(\mathrm{m})\end{array}$ \\
\hline 10 & 6.400 & 7.5 & 15 \\
20 & 1.600 & 15 & 30 \\
40 & 400 & 30 & 60 \\
\hline
\end{tabular}

\section{RESULTADOS}

0 planejamento dos levantamentos de campo foi feito preocupando-se em mapear a maior extensão possível sobre as valas de resíduos, bem como verificar a possibilidade de determinar a direção do fluxo do material contaminante.

0 traçado de 7 linhas de investigação sobre o terreno é mostrado na Figura 3.

Neste trabalho foram realizadas 2970 leituras de condutividade aparente percorridas em 495 estações de investigação, espaçadas de 10 em $10 \mathrm{~m}$. Em outro trabalho na mesma área Fachin et al. (2006) estabeleceram para áreas não contaminadas, valores de condutividade menores que $20 \mathrm{mS} / \mathrm{m}$. Entre 20 e $40 \mathrm{mS} / \mathrm{m}$ para áreas de transição e acima de $40 \mathrm{mS} / \mathrm{m}$ para áreas contaminadas.

Na Figura 4 estão os perfis de condutividade elétrica das linhas EM-0, EM-4, EM-5 e EM-6. Na linha EM-0, localizada sobre a estrada que margeia a área de deposição de resíduos, os 


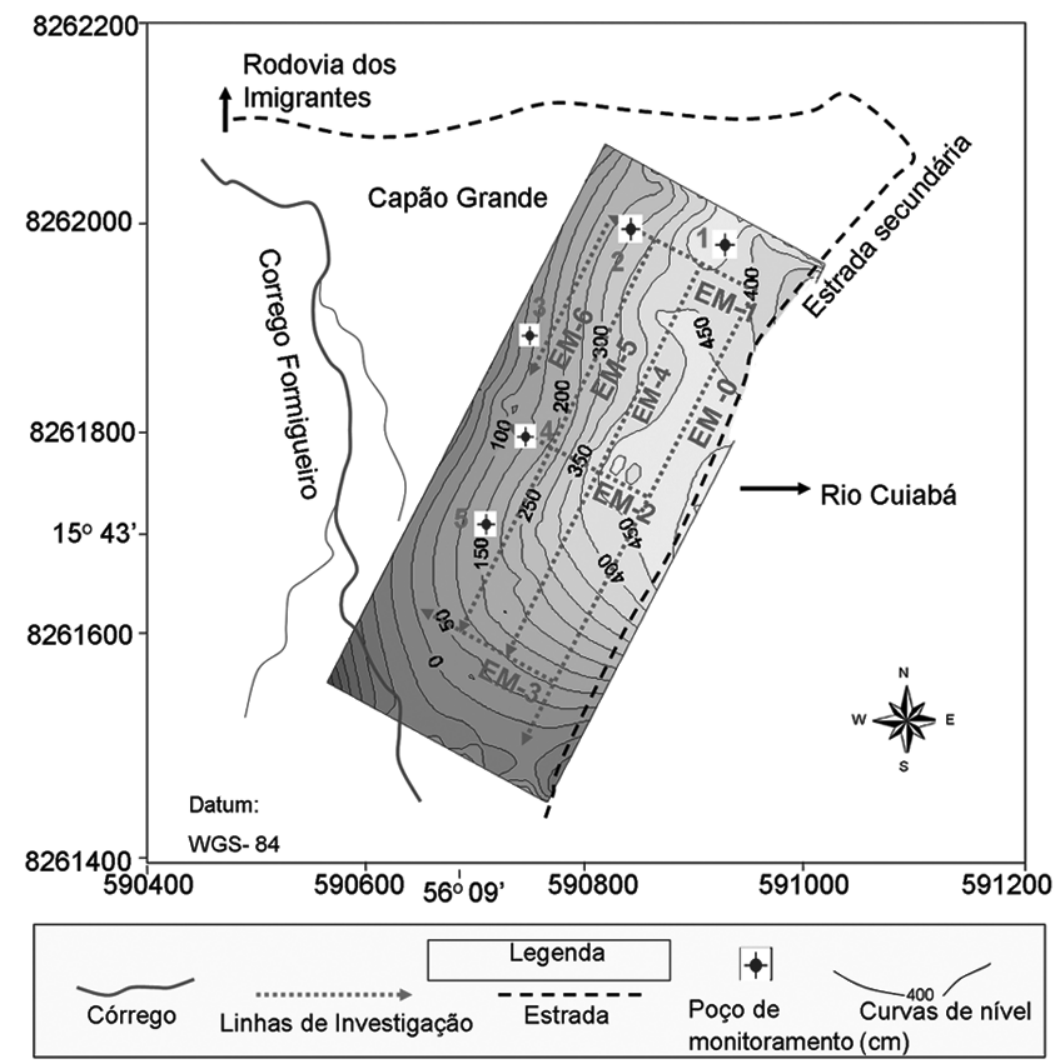

Figura 3 - Mapa de localização dos perfis de investigação e poços de monitoramento.

valores de condutividade aparente estão mais acentuados entre as posições 70 e $230 \mathrm{~m}$, sendo que a profundidades teóricas a partir de $15 \mathrm{~m}$ os valores de condutividade aparente começaram a acentuar-se registrando valores entre 25 e $50 \mathrm{mS} / \mathrm{m}$. Assim, pode ser caracterizado que a contaminação nessa linha está em níveis inferiores a $20 \mathrm{~m}$.

Na linha EM-4 a condutividade elétrica apresenta os maiores valores entre as posições 50 e $230 \mathrm{~m}$ da linha, variando entre $40 \mathrm{mS} / \mathrm{m}$ e $70 \mathrm{mS} / \mathrm{m}$ da superfície até a profundidade teórica aproximada de $50 \mathrm{~m}$. A partir da posição $250 \mathrm{~m}$ a condutividade apresenta valores abaixo de $20 \mathrm{mS} / \mathrm{m}$, indicando uma área sem contaminação na parte superior, podendo haver pequena contaminação na parte inferior.

0 perfil da linha EM-5 é a que apresenta a maior área contaminada. Os valores de condutividade aparente mais acentuados (50 a $70 \mathrm{mS} / \mathrm{m}$ ) seguem desde 0 início da linha em quase todas as profundidades até a posição de $260 \mathrm{~m}$. Como o início da linha foi executado no limite da área, acredita-se que a contaminação possa ultrapassar o limite da área. Verifica-se nesta linha a in- fluência marcante da posição das valas de rejeitos sobre os maiores valores de condutividade aparente verificados na área. Pelas informações fornecidas pelos técnicos da empresa do curtume e pela verificação no local, as valas estão situadas em uma região aproximada de $50 \mathrm{~m}$ na direção SE-NW estendendo-se por mais ou menos 200 m na direção NE-SW.

A linha EM-6 só pode ser levantada nos seus primeiros $200 \mathrm{~m}$ devido à intersecção de uma cerca de arame no local. Esta linha localizada mais a jusante da área apresentou valores de condutividade aparente variando entre 25 e $45 \mathrm{mS} / \mathrm{m}$ das posições de 0 a $130 \mathrm{~m}$ em quase todas as profundidades. Possivelmente, essa linha está sendo irrigada pela percolação do material contaminado visualizado na linha EM-5. Após a posição $130 \mathrm{~m}$, os valores de condutividade decrescem chegando a $5 \mathrm{mS} / \mathrm{m}$ próximos à superfície.

As linhas de investigação de condutividade aparente adquiridas nas posições perpendiculares à estrada, sentido SE-NW (Fig. 5), linhas EM-1, EM-2 e EM-3 confirmam uma predominância de contaminação até a profundidade aproximada de 


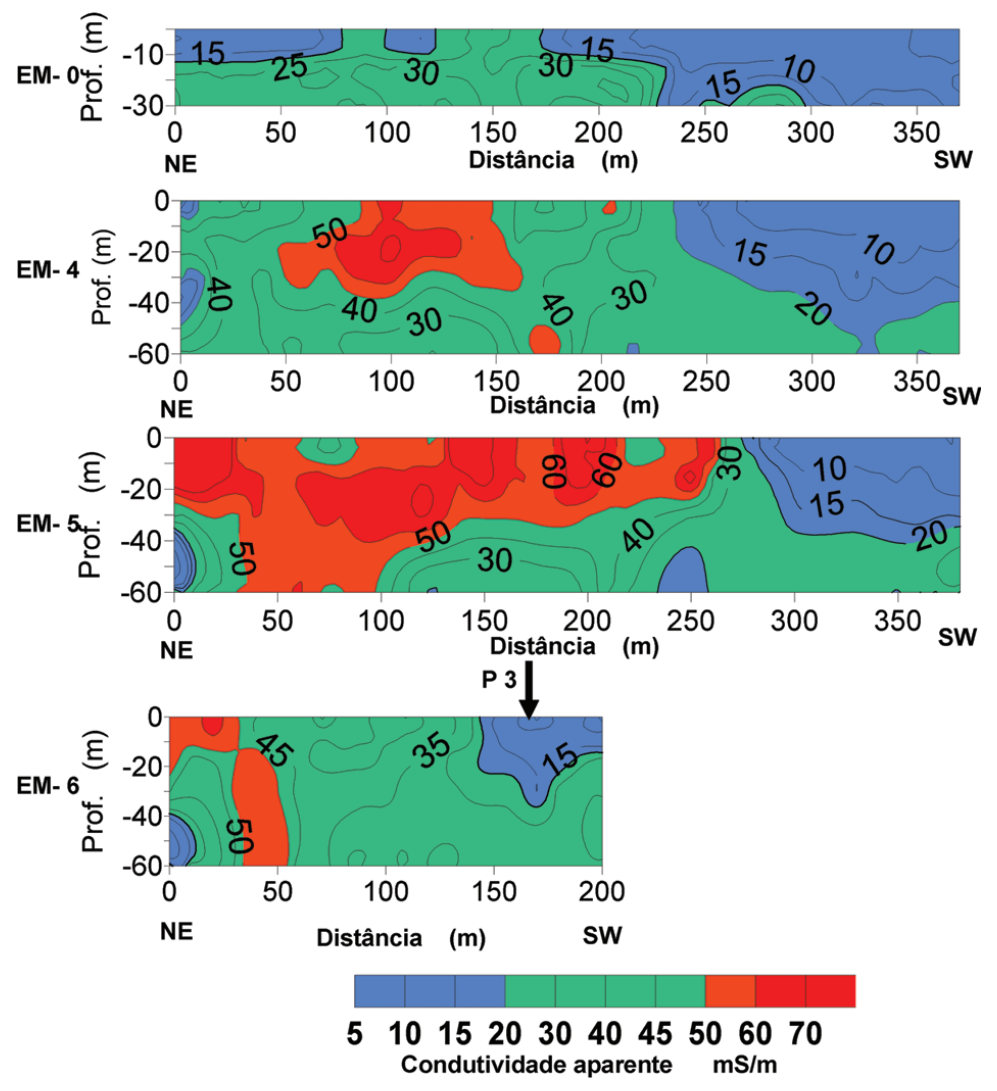

Figura 4 - Seções de condutividade aparente das linhas EM-0, EM-4, EM-5 e EM-6 sentido NE-SW da área de disposição de resíduos.

50 m (linhas EM-1 e EM-2). Nota-se uma nítida ausência de valores acentuados de condutividade nos $100 \mathrm{~m}$ da linha EM3, localizada próximo do final da área, a jusante do lançamento de resíduos.

Esta ausência de valores acentuados de condutividade e por correlação de contaminação na parte mais a jusante da área no sentido NE-SW talvez pudesse ser explicada pelo inúmeros dobramentos de filitos característicos dessa região.

Este pressuposto poderia vir a ser confirmado pela característica de alguns poços de monitoramento encontrados a jusante da área e que, mesmo na época das chuvas, apresentavamse secos, contribuindo para a afirmação de que esta abrupta interrupção do fluxo de água subterrânea no sentido NE-SW, e por conseguinte da contaminação, como indicam o perfil de condutividade aparente EM-3, poderiam ser fruto da mudança da característica geológica do subsolo.

0 poço de monitoramento $n^{\circ} 4$, localizado próximo do final da linha EM-2 (Fig. 5) apresentou a amostra de água com 0 maior nível da presença de cromo, com uma média de $5,44 \mathrm{mg} / \mathrm{L}$
(Tab. 2), onde os valores de condutividade aparente registrados pelo levantamento EM também são acentuados e próximos de $50 \mathrm{mS} / \mathrm{m}$.

Tabela 2 - Análises descritivas da concentração de cromo nos poços de monitoramento (Lannes, 2002).

\begin{tabular}{|c|c|c|c|c|c|}
\hline Substância & Poço & $\mathrm{N}$ & $\begin{array}{c}\text { Média } \\
(\mathrm{mg} / \mathrm{L})\end{array}$ & $\begin{array}{c}\text { Mediana } \\
(\mathrm{mg} / \mathrm{L})\end{array}$ & $\begin{array}{c}\text { Desvio- } \\
\text { padrão }\end{array}$ \\
\hline \multirow{3}{*}{ Cromo* } & P1 & 6 & 2,9767 & 2,2950 & 2,6956 \\
& P2 & 8 & 1,9950 & 1,8300 & 1,0804 \\
& P3 & 11 & 1,5427 & 1,3100 & 0,5453 \\
& P4 & 12 & 5,4483 & 1,4600 & 13,3098 \\
\hline
\end{tabular}

*Padrão de potabilidade - Port. MS-518/2004 - Cromo 0,05 (mg/L).

A análise dos mapas de condutividade aparente, mostradas em planta (Fig. 6) permitem uma comparação da mobilidade do fluxo contaminante nas direções NE-SE e SE-NW, levando-nos a considerar que apesar da área apresentar declividade nas duas direções, na direção SE-NW houve uma maior uniformidade nos altos valores de condutividade aparente registrados ao contrário 

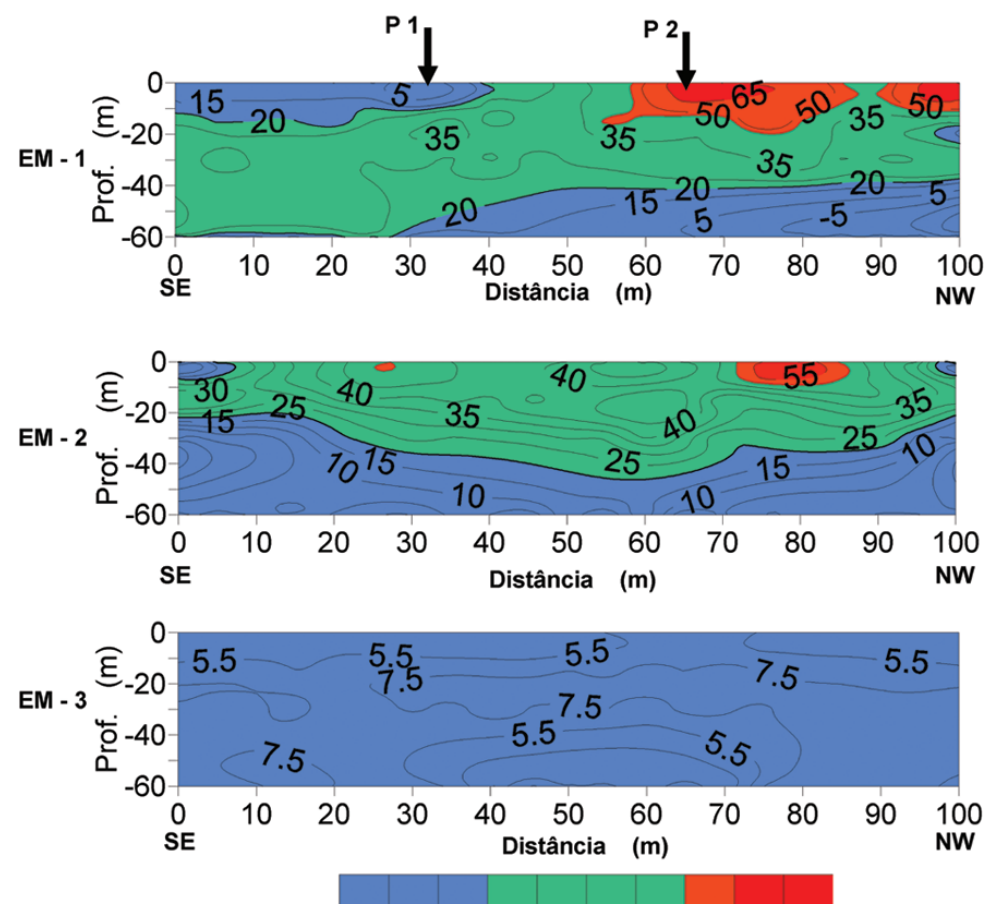

$5 \quad 10152030 \quad 4045506070$

Figura 5 - Seções de condutividade aparente das linhas de investigação EM-1, EM-2 e EM-3 sentido SE-NW da área de resíduos.

da direção NE-SW em que houve um decréscimo considerável dos valores de condutividade aparente quando se aproximou da direção a jusante da área.

Os perfis e mapas de condutividade aparente evidenciaram valores de condutividade aparente ( $>20 \mathrm{mS} / \mathrm{m}$ ) até a profundidade teórica de $30 \mathrm{~m}$, diminuindo consideravelmente com 0 avanço da profundidade até $60 \mathrm{~m}$.

\section{CONCLUSÕES}

A deposição inadequada de rejeitos industriais pode vir a configurar um problema de grandes dimensões para a sociedade, haja a vista a característica de certos tipos de poluentes industriais, como é o caso do cromo na indústria do couro.

Anomalias de condutividade puderam ser relacionadas à presença de compostos inorgânicos presentes nos resíduos da industrialização do couro e percolação destes compostos no ambiente geológico, comprovada por análises químicas das águas subterrâneas. Desta forma, há uma correlação direta entre anomalias de alta condutividade e elevadas concentrações de cromo.

Os perfis e mapas de condutividade aparente evidenciaram altos valores de condutividade aparente (>20 mS/m) até a pro- fundidade teórica de $30 \mathrm{~m}$, diminuindo consideravelmente com 0 avanço da profundidade até $60 \mathrm{~m}$.

Apesar de não ser possível verificar com detalhes a locação das antigas valas de resíduos no terreno, contudo fica claro que a locação dos altos valores de condutividade aparente desenham com uma certa aproximação, o mapa das valas no terreno.

Os trabalhos de mapeamento de valores de condutividade em profundidade demonstraram que existe uma direção predominante na propagação da pluma de contaminação no sentido SE-NW.

Medidas de condutividade aparente na camada de aterro até $7,5 \mathrm{~m}$ de profundidade ficaram em torno de 40 a $50 \mathrm{mS} / \mathrm{m}$ no limite NW da área, indicando que a pluma deve estar ultrapassando os limites da área interditada. A confirmação ou não desta suspeita poderia ser realizada através de novas pesquisas adjacentes a área investigada.

Conclui-se que apesar do poder poluente dos materiais depositados sobre a área, o mapeamento mostrou que se não houver um veiculo condutor (água) que propague o contaminante para a região SW, não haverá fluxo nesta direção e sim na direção NW. Esta afirmação explica-se pelo fato de que os compostos de 

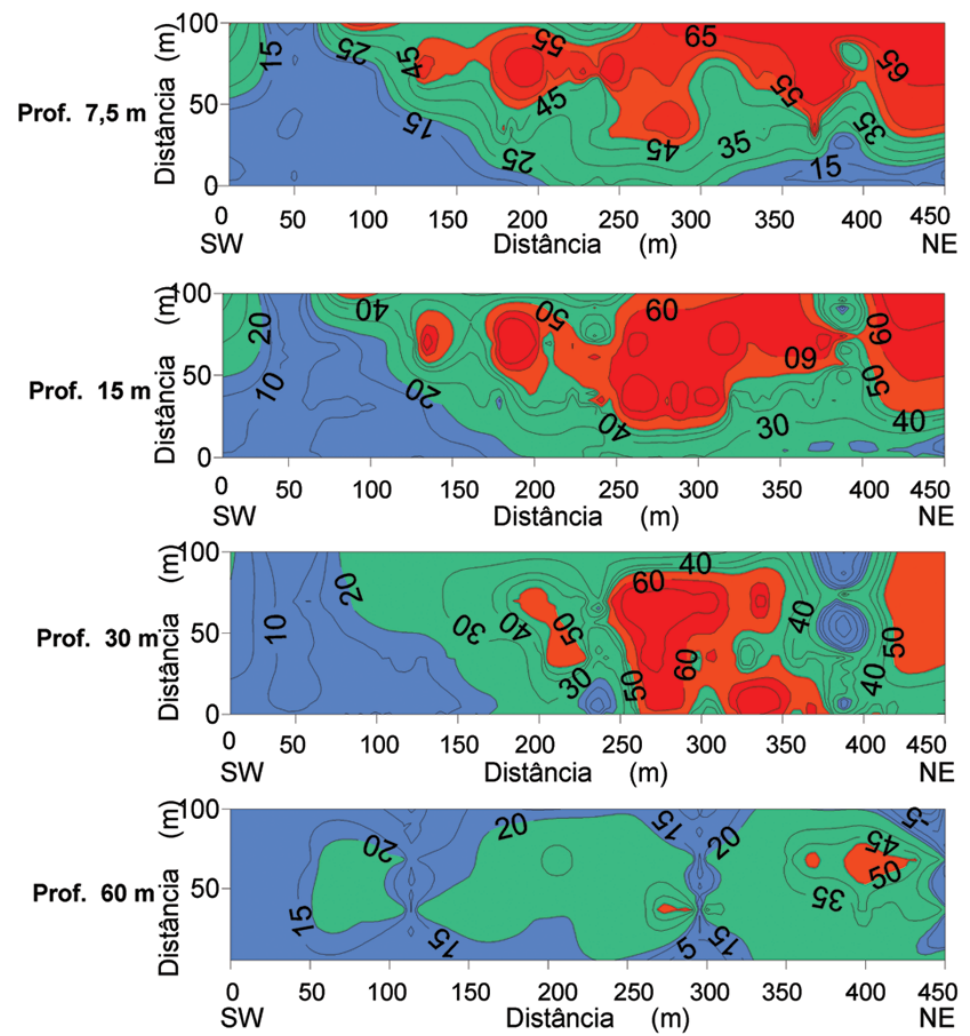

5101520304045506070

Condutividade aparente $\mathrm{mS} / \mathrm{m}$

Figura 6 - Mapa de condutividade aparente da área de resíduos sólidos do curtume localizado no município de Várzea Grande nas profundidades teóricas de 7,5 m, 15 m, 30 m e 60 m.

cromo solubilizam-se em água, através da hidrólise do íon $\mathrm{Cr}^{+6}$, que contribui para 0 aumento da condutividade com a formação dos eletrólitos.

A disposição inadequada de resíduos de cromo, além da contaminação da água, pode contribuir para a bioacumulação, fenômeno que leva ao aumento da concentração da substância tóxica no tecido dos organismos nos níveis mais elevados da cadeia alimentar. A ingestão desses organismos pelo homem pode causar graves danos à saúde sendo considerado substância carcinogênica.

\section{AGRADECIMENTOS}

Os autores agradecem à Universidade Federal de Mato Grosso, UFMT, à Fundação de Amparo à Pesquisa do Estado de Mato Grosso pelo financiamento (Projeto - Estudo da disposição final de resíduos sólidos de curtume como fonte de contaminação em águas subterrâneas). Ao prof. Dr. Renato Blatt Migliorini pelas valiosas contribuições no entendimento da hidrogeologia local. À Universidade do Estado de Mato Grosso - UNEMAT pela liberação do Prof. Luiz Fernando Jorge da Cunha para a pósgraduação. Aos alunos da graduação em Geologia da UFMT pelo auxílio na aquisição dos dados.

\section{REFERÊNCIAS}

ELIS VR. 2003. Geofísica aplicada ao estudo da poluição de solos e águas subterrâneas. In: V Escola de Verão de Geofísica, IAG/USP, São Paulo, SP.

FACHIN SJS, HUBER F, SHIRAIWA S, BORGES WR \& MIGLIORINI RB. 2006. Aplicação de métodos geofísicos para identificar áreas contaminadas por resíduos de um curtume. Revista Brasileira de Geofísica, SBGf, 24(1): 129-138.

GOLDEN SOFTWARE INC. 1995. SURFER ${ }^{\text {TM }}$ for Windows V8. Reference manual. Golden, Colorado, USA.

KOETZ PR, FARIA OLV \& NUNES WA. 1995. Tratamento de efluentes homogeneizados de curtume por digestão anaeróbia em reatores de fluxo ascendente. Rev. Bras. Agrociência, 1(1): 23-29. 
LANDIM PMB. 2003. Análise estatística de dados geológicos. 2 ed. São Paulo, Unesp. 253 p.

LANNES S. 2002. Avaliação da qualidade da água subterrânea na área de disposição do lodo proveniente do curtume Berto S/A - Várzea Grande/MT. Instituto de Saúde Coletiva (Dissertação de Mestrado), UFMT, Cuiabá-MT, 100 p.

McNEILL JD. 1980. Electromagnetic terrain conductivity measurement at low induction numbers. Tech. Note TN-6, Geonics Ltd., Mississauga,
Ontário, Canadá, 14 p.

MIGLIORINI RB. 1999. Hidrologia em Meio Urbano. Tese de Doutorado. Instituto de Geociências. Universidade de São Paulo. 146 p.

MINISTÉRIO DA SAÚDE. 2004. Portaria № 518, de 25 de março de 2004. Brasília, Brasil.

RAY D, EARY LE \& ZACHARA JM. 1989. Environmental chemistry of chromium. Sci. Total Environ., 86(1-2): 15-23.

\section{NOTAS SOBRE OS AUTORES}

Luiz Fernando Jorge da Cunha. Engenheiro Civil formado pela Universidade Federal de Mato Grosso - UFMT (1985). Mestre em Física e Meio Ambiente pela Universidade Federal de Mato Grosso (2005). Doutor em Geofísica pela Universidade Federal da Bahia (2009). Desde 1994 é docente da Universidade do Estado de Mato Grosso - UNEMAT, Faculdade de Ciências Exatas do Departamento de Matemática, atuando em Geoestatística, e geofísica aplicada à hidrogeologia e estudos ambientais.

Shozo Shiraiwa. Doutor em Geofísica pela Universidade de São Paulo (1994). Pesquisador associado da Universidade Federal de Mato Grosso - UFMT. Orientador de doutorado e mestrado em Física Ambiental e mestrado em Recursos Hídricos da Universidade Federal de Mato Grosso, trabalhando com métodos geofísicos aplicados à investigação ambiental. 